Erfan Dani S,Livia Windiana, dan Nur Ocvanny A. 2018. Analisis Prilaku Ibu Rumah Tangga di Perkotaan Terhadap Pemanfaatan Teknologi Aquavertikulture Inovasi Pengembangan Budidaya Pertanian dan Perikanan pada Lahan Sempit (Studi Kasus ibu PKK di Kelurahan Pandanwangi, Kecamatan Blimbing, Kota Malang ) Journal Viabel Pertanian. (2018), 12(2) 1-10

\title{
Analisis Prilaku Ibu Rumah Tangga di Perkotaan Terhadap Pemanfaatan Teknologi Aquavertikulture Inovasi Pengembangan Budidaya Pertanian dan Perikanan pada Lahan Sempit \\ (Study Kasus Ibu PKK di Kelurahan Pandanwangi, Kecamatan Blimbing, Kota Malang) \\ Erfan Dani $S^{1^{* *}}$, Livia Windiana ${ }^{2)}$ dan Nur Ocvanny $A^{3)}$

\author{
Fakultas Pertanian dan Peternakan, Universitas Muhammadiyah Malang \\ Jl. Raya Tlogomas 246 Malang, Jawa Timur, Indonesia \\ ${ }^{*}$ Email Author: erfan_dhani@yahoo.com
}

\begin{abstract}
ABSTRAK
Urban is the destination and center of all community activities. According to Harahap, (2013) states that each population has a significant increase and population growth. Communities living in cities are highly demanded to have high productivity in order to compete and meet their individual needs. But it cannot be denied that there are some urban communities who are not able to compete with the population. The profession of a housewife in one example is a society that is not competitive and unproductive. Based on national socio-economic survey data from the Central Bureau of Statistics (2004) stated that most mothers in cities from 40 years who have children are $63.3 \%$ of households and $29.6 \%$ of them are career women. This is because being a housewife in a city depends more on the husband's income. Lately in Indonesia there has been considerable economic upheaval in various sectors that have enabled an increase in various needs in various regions of Indonesia. This condition requires housewives to play the brain to support family needs. Aquaverticuture insulation of agricultural development and efforts in increasing productive business of housewives is a solution that can be offered in supporting the economy, this implementation program will be implemented in the community of housewives in urban areas, while the areas to be piloted in this program are the Circle of Friends Dahlia and Gardania at Sulfate Gardens Housing, Pandanwangi Village, Blimbing, Malang City.
\end{abstract}

Keywords: Household Conditions, Productivity Levels, and Aquaverticulture

\section{PENDAHULUAN}

Perkotaan merupakan tujuan dan pusat segala aktivitas masyarakat. Menurut (Harahap, 2013) menyatakan bahwa tiap tahunnya mengalami peningkatan dan pertumbuhan penduduk yang signifikan. Hal ini dikarenakan terjadinya urbanisasi penduduk desa ke kota baik sekedar untuk mengadu nasib ataupun menuntut ilmu. Kondisi tersebut membawa dampak sosial yang berakibat tingginya iklim kompetitif dalam kehidupan masyarakat perkotaan. Masyarakat perkotaan menurut (Luthfia, 2013) menyatakan terdapat 2 tipe masyarakat, yaitu (1) kelompok masyarakat yang menang dan berhasil dalam iklim kompetisi perkotaan dan (2) kelompok masyarakat yang kalah dan tersingkir. Sehingga masyarakat yang tinggal di wilayah perkotaan sangat dituntut memiliki produktifitas yang tinggi agar dapat bersaing dan memenuhi kebutuhannya masing-masing. Namun tidak dapat dipungkiri bahwa pada tipe 
Erfan Dani S,Livia Windiana, dan Nur Ocvanny A. 2018. Analisis Prilaku Ibu Rumah Tangga di Perkotaan Terhadap Pemanfaatan Teknologi Aquavertikulture Inovasi Pengembangan Budidaya Pertanian dan Perikanan pada Lahan Sempit (Studi Kasus ibu PKK di Kelurahan Pandanwangi, Kecamatan Blimbing, Kota Malang ) Journal Viabel Pertanian. (2018), 12(2) 1-10

kedua masyarakat perkotaan merupakan masyarakat yang tidak mampu bersaing sehingga dipastikan sangat kesulitan dalam pemenuhan kebutuhan hidup di perkotaan.

Profesi ibu rumah tangga di perkotaan adalah salah satu contoh masyarakat yang tidak mampu bersaing dan tidak produktif. Berdasarkan data survey sosial ekonomi nasional dari (Statistics Indonesia, 2014) menyatakan bahwa sebagian besar ibu di wilayah perkotaan yang berusia kurang dari 40 tahun yang telah memiliki anak yaitu terdapat 63,3\% yang mengurus rumah tangga saja dan terdapat $29,6 \%$ yang berprofesi sebagai wanita karir. Hal ini dikarenakan menjadi ibu rumah tangga di wilayah perkotaan lebih mengandalkan pendapatan suami. Akan tetapi akhir-akhir ini di Indonesia terjadi pergolakan ekonomi yang cukup berdampak pada berbagai sektor usaha yang mengakibatkan kenaikan harga kebutuhan pokok mayarakat di berbagai wilayah di Indonesia. Sehingga kondisi tersebut menuntut ibu rumah tangga mememutar otak untuk menunjang kebutuhan keluarga.

Kegiatan rutin yang dilakukan ibu rumah tangga biasanya kegiatan yang tidak produktif seperti berkumpul untuk ngerumpi ataupun hanya sekedar memasak. Namun pada dasarnya kondisi tersebut membuat jenuh para ibu rumah tangga di perkotaan. Hal ini dikarenakan ibu rumah tangga hanya bergantung pada pendapatan suami dan tidak terdapat kegiatan produktif yang dapat dilakukan. Padahal dari 40 orang ibu rumah tangga pada Paguyuban Dahlia dan Gardania adalah lulusan S-1 (Sarjana strata 1). Insiatif kegiatan dalam meningkatkan usaha produktif ibu rumah tangga sangat diperlukan agar ibu rumah tangga yang tidak bekerja tersebut dapat menunjang kebutuhan keluarga. Banyak hal yang dapat dilakukan oleh ibu rumah tangga di perkotaan seperti berkebun, berdagang ataupun menciptakan usaha produktif. Namun banyak hal yang menjadi penghambat berkembangnya seorang ibu dirumah seperti kurangnya modal untuk usaha ataupun keterbatasan lahan untuk berkebun.

Oleh karena itu untuk meningkatkan usaha produktif dari ibu rumah tangga di perkotaan maka diperlukan cara untuk ibu rumah tangga melakukan usaha dirumah dengan memanfaatkan lahan sempit tanpa meninggalkan kegiatan yang sering dilakukan seperti ngerumpi atau bergosip. Hal ini dikarenakan fenomena tersebut justru memberi suatu gebrakan baru bahwa wanita pun mampu melakukan terobosan baru. Secara tidak langsung kekuatan ini justru muncul dari sinergitas kelemahan (sifat harfiah wanita cenderung lebih suka berkumpul sesamanya untuk ngerumpi, arisan dan bergosip) dan kelebihan (suka akan keindahan, kecantikan dan kebersihan) yang dimiliki oleh setiap wanita. Apapun usaha yang dilakukan akan dapat menjadi pelopor dan penggerak masyarakat berdasarkan sikap sosial yang selalu dilakukan oleh ibu rumah tangga.

Melihat kondisi yang demikian itu, kepedulian Perguruan Tinggi sangat diharapkan untuk melakukan pembinaan kepada ibu rumah tangga dalam peningkatan usaha produktif memanfaatkan lahan perkarangan sempit dengan cara melakukan sebuah pelatihan dengan konsep aquavertikultur inovasi pengembangan budidaya pertanian dan perikanan skala rumah tangga. Hal tersebut bertujuan untuk melaksanakan kerjasama antara ibu rumah tangga, perguruan tinggi dan mitra usaha. Selain itu memunculkan usaha produktif ibu rumah tangga untuk menunjang perekonomian keluarga dari hasil produksi tanaman dan ikan. 
Erfan Dani S,Livia Windiana, dan Nur Ocvanny A. 2018. Analisis Prilaku Ibu Rumah Tangga di Perkotaan Terhadap Pemanfaatan Teknologi Aquavertikulture Inovasi Pengembangan Budidaya Pertanian dan Perikanan pada Lahan Sempit (Studi Kasus ibu PKK di Kelurahan Pandanwangi, Kecamatan Blimbing, Kota Malang ) Journal Viabel Pertanian. (2018), 12(2) 1-10

\section{METODE}

Metode yang digunakan dalam pemecahan masalah yang di hadapi oleh mitra/ ibu rumah tangga di perumahan sulfat garden Malang dilakukan secara partisipasitif, ceramah, pelatihan budidaya dan pengolahan produk serta pendampingan pemasaran produk segar maupum olahan.

\section{Sosisalisasi dengen menggunakan metode ceramah}

agar ibu rumah tangga mengetahui, memahami dan lebih responsif memanfaatkan halaman rumahnya untuk hal yang lebih ekonomis.

\section{Pelatihan budidaya pengembangan tanaman dan ikan dengan metode aqua} vertikultur.

Metode sosialisasi/ pelatihan ini dengan cara :

a) memberikan bantuan teknologi dan benih untuk budidaya aquavertikultur

b) memberikan demplot budidaya aqua vertikultur

c) melakukan pelatihan teknik budidaya tanaman secara hidroponik yang menerapkan sistem vertikulture

d) melakukan pelatihan pembudiayaan ikan dengan sistem aquaponik

e) melakukan pelatihan pengecekan kualitas air, kesehatan tanaman dan ikan.

\section{Pendampingan pemasaran dan pengolahan produk aqua vertikultur}

Metode pendampingan ini dengan cara:

a) memberikan pelatihan dan pendampingan dalam manajemen produksi

b) memberikan pelatihan dan pendampingan dalam pemasaran

c) memberikan pelatihan dan pendampingan dalam penetapan SOP

d) memberikan pelatihan dan pendampingan dalam memaksimalkan output aqua vertikultur dengan pengembangan media atau bahan yang tersedia seperti sampah dapur dijadikan sebagai bahan pupuk organik

e) memberikan pelatihan dan pendampingan dalam pengolahan produk yang dihasilkan.

\section{Evaluasi Pelaksanaan Program}

Melakukan evaluasi secara keseluruhan tentang keberhasilan program pengabdian dengan monitoring kegiatan pelaksanaan dan pendampingan, penjadwalan waktu pengabdian, serta memastikan semua proses dan tahapan pengabdian sesuai dengan mekanisme yang telah ditentukan. Proses evaluasi ini menggunakan skala likert. Menurut (Hendri, 2009) skala likert merupakan teknik self report bagi pengukuran sikap dimana subjek diminta untuk mengindikasikan tingkat kesetujuan atau ketidaksetujuan mereka terhadap masing- masing pernyataan.

Evaluasi ini berdasarkan pada beberapa daftar pertanyaan yang bersifat positif dan negatif yang terdapat dalam kuisioner. Kuisioner ini diberikan kepada responden sebelum dan sesudah dilakukannya Program Aquaverticulture. Analisis ini didukung oleh penilaian berdasarkan pendapat responden yaitu Ibu rumah tangga di Kelurahan Pandanwangi. Dalam analisis ini menggunakan pengukuran sesuai skala Likert dimana masing-masing pertanyaanr diberi nilai sesuai dengan item jawaban yang dipilih dan masing-masing jawaban memiliki bobot penilaian jawaban yang berbeda berdasarkan skala Likert yang dipergunakan. Jadi apabila jawaban: 
Erfan Dani S,Livia Windiana, dan Nur Ocvanny A. 2018. Analisis Prilaku Ibu Rumah Tangga di Perkotaan Terhadap Pemanfaatan Teknologi Aquavertikulture Inovasi Pengembangan Budidaya Pertanian dan Perikanan pada Lahan Sempit (Studi Kasus ibu PKK di Kelurahan Pandanwangi, Kecamatan Blimbing, Kota Malang ) Journal Viabel Pertanian. (2018), 12(2) 1-10

$\begin{array}{lll}\text { Setuju } & \text { diberi bobot } & 4 \\ \text { Netral } & \text { diberi bobot } & 3 \\ \text { Tidak Setuju } & \text { diberi bobot } & 2 \\ \text { Sangat tidak setuju } & \text { diberi bobot } & 1\end{array}$

Setelah kuisioner telah dijawab responden, maka selanjutnya yaitu mengolah data kemudian membuat tabel pengukuran dari setiap pertanyaan yang menggunakan skala Likert. Contoh tabel pengukuran dalam skala likert dapat dilihat pada Tabel 1.Adapun rumus pengukuran yaitu sebagai berikut.

Tabel 1. Pengukuran Nilai Indeks Pada Masing-Masing Pertanyaan dengan Skala Likert

\begin{tabular}{|l|c|c|c|c|c|}
\hline Pertanyaan & $\begin{array}{c}\text { Skor Masing- } \\
\text { Masing Skala }\end{array}$ & Total Skor & $\begin{array}{c}\text { Skor } \\
\text { Maksi } \\
\text { mum }\end{array}$ & $\begin{array}{c}\text { Skor } \\
\text { Mini } \\
\text { mum }\end{array}$ & Nilai Indeks \\
\hline $\begin{array}{l}\text { Pertanyaan 1 } \\
\text { hingga 12 }\end{array}$ & $\mathrm{S}=\mathrm{T}$ x Pn & $\begin{array}{c}\mathrm{TS}=\mathrm{S}_{1}+\mathrm{S}_{2} \\
+\mathrm{S}_{3}+\mathrm{S}_{4}+\mathrm{S}_{5}\end{array}$ & $\mathrm{Y}$ & $\mathrm{X}$ & $\begin{array}{l}\text { Rumus Indeks } \\
(\%)=\mathrm{TS} /(\mathrm{Y} \mathrm{x} \\
100)\end{array}$ \\
\hline
\end{tabular}

Keterangan :

S

$\mathrm{T}$

Pn

TS

Likert)

$\mathrm{S}_{1}, \mathrm{~S}_{2}$

$\mathrm{Y}$

$\mathrm{X}$
$=$ Skor Masing-Masing Skala

$=$ Total jumlah responden yang memilih

$=$ Pilihan angka skor Likert

$=$ Total Skor (Hasil penjumlahan masing-masing skor pada skala

$=$ Skor masing-masing skala Likert

$=$ skor tertinggi Likert $\mathrm{x}$ jumlah responden

$=$ skor terendah Likert $\mathrm{x}$ jumlah responden

Setelah dilakukan analisis nilai indeks, maka selanjutnya yaitu mencari interval (rentang jarak) dan interpretasi persen untuk mengetahui keterangan hasil nilai indeks.

Tabel 2. Prosentase nilai

\begin{tabular}{|c|c|}
\hline JAWABAN & KETERANGAN \\
\hline $0 \%-19.99 \%$ & SANGAT TIDAK SETUJU \\
\hline $20 \%-39.99 \%$ & TIDAK SETUJU \\
\hline $40 \%-59.99 \%$ & NETRAL \\
\hline $60 \%-79.99 \%$ & SETUJU \\
\hline $80 \%-100 \%$ & SANGAT SETUJU \\
\hline
\end{tabular}

\section{HASIL dan PEMBAHASAN}

Adapun hasil yang dicapai pada program kemitraan masyarakat dengan konsep Aquaverticulture dalam peningkatan usaha produktif ibu rumah dimulai dengan metodemetode pelaksanaan sebagai berikut: 
Erfan Dani S,Livia Windiana, dan Nur Ocvanny A. 2018. Analisis Prilaku Ibu Rumah Tangga di Perkotaan Terhadap Pemanfaatan Teknologi Aquavertikulture Inovasi Pengembangan Budidaya Pertanian dan Perikanan pada Lahan Sempit (Studi Kasus ibu PKK di Kelurahan Pandanwangi, Kecamatan Blimbing, Kota Malang ) Journal Viabel Pertanian. (2018), 12(2) 1-10

\section{Sosisalisasi Aquaverticulture kepada ibu rumah tangga}

Sosialisasi ini dilakukan pada kelompok ibu rumah tangga di Kelurahan Pandanwangi yang bertempat pada perumahan sulfat garden. Kurang lebih 50 ibu rumah tangga mendapatkan sosialisasi mengenai konsep aquavertikulture yang akan diterapkan oleh agar ibu rumah tangga mengetahui kelebihan konsep aquavertikultur yang merupakan konsep kombinasi antara konsep aquaculture yaitu konsep budidaya perikanan dan verticulture yaitu konsep budidaya tanaman secara vertikal yang dapat menciptakan inovasi yang efisien, sehingga dengan harapan ibu rumah tangga lebih responsif memanfaatkan halaman rumahnya untuk hal yang lebih ekonomis.
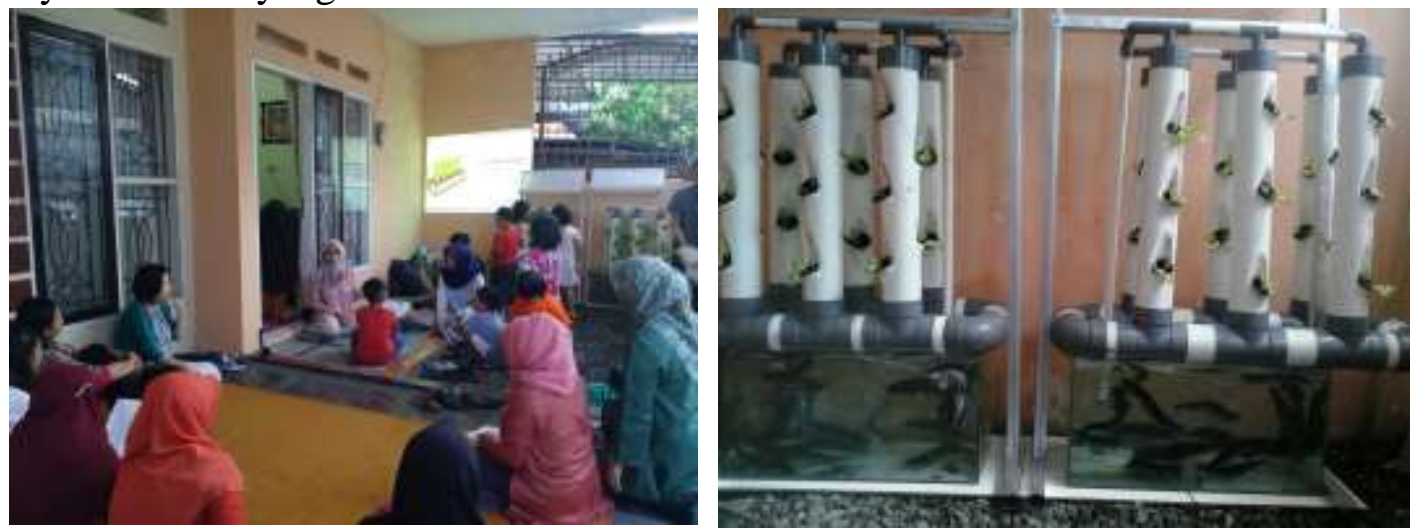

Gambar 1. Sosisalisasi Aquaverticulture kepada ibu rumah tangga. Ket a. Pemaparan materi, b. Aquavertikultur

Menurut (Setyono, 2004) Akuakultur yang di Indonesia dikenal dengan istilah budidaya air dibedakan menjadi dua, yaitu budidaya air tawar dan budidaya air laut dan Akuakultur sebagai usaha untuk memproduksi biota air pada skala besar (komersial) berkaitan dengan beberapa disiplin ilmu, termasuk ilmu pertanian, perikanan, hukum, ekonomi, kimia, teknik dan biologi. Pembudidaya harus familiar dan mengetahui dasar-dasar dari ilmu tersebut untuk menunjang keberhasilan usahanya. Selain itu vertikultur adalah sistem budidaya pertanian yang dilakukan secara vertikal atau bertingkat, baik indoor maupun outdoor (Lukman, 2011). Penerapan vertikultur tersebut dikombinasikan dengan sistem hidroponik agar lebih efisien dalam penerapan aquavertikulture. Jenis hidroponik yang digunakan adalah jenis NFT yaitu menurut (Wibowo \& Asriyanti, 2013) NFT merupakan model budidaya hidroponik dengan meletakkan akar tanaman pada lapisan air yang dangkal. Air tersebut tersirkulasi dan mengandung nutrisi sesuai kebutuhan tanaman. Perakaran bisa berkembang di dalam larutan nutrisi. Karena di sekeliling perakaran terdapat selapis larutan nutrisi, maka sistem ini dikenal dengan nama nutrient film technique (NFT).

\section{Pelatihan budidaya pengembangan tanaman dan ikan dengan metode aqua vertikultur.}

Metode sosialisasi/ pelatihan ini dengan cara :

a. Memberikan bantuan teknologi dan benih untuk budidaya aquavertikultur

Teknologi yang diberikan kepada ibu rumah tangga di Kelurahan Pandanwangi yaitu berupa bantuan inovasi teknologi akuavertikulture yang berasal dari kombinasi konsep 
Erfan Dani S,Livia Windiana, dan Nur Ocvanny A. 2018. Analisis Prilaku Ibu Rumah Tangga di Perkotaan Terhadap Pemanfaatan Teknologi Aquavertikulture Inovasi Pengembangan Budidaya Pertanian dan Perikanan pada Lahan Sempit (Studi Kasus ibu PKK di Kelurahan Pandanwangi, Kecamatan Blimbing, Kota Malang ) Journal Viabel Pertanian. (2018), 12(2) 1-10

budidaya ikan dan tanaman yang diterapkan oleh ibu rumah tangga pada lahan sempit pekarangan rumah masing-masing, teknologi verticulture merupakan teknologi budidaya tanaman secara vertikal berbasis hidroponik, sehingga pengenalan teknologi kepada ibu rumah tangga tersebut diperkenalkan secara menyeluruh yaitu dimulai dengan memanfaatkan bahan sederhana seperti botol bekas sebagai sarana teknologi budidaya tanaman. Kemudian teknologi vertikulture disini dikombinasikan dengan teknologi aquakulture dengan harapan kombinasi tanaman dan ikan akan menciptakan siklus yang berkesinambungan satu sama lain.

Adapun benih sayuran yang digunakan yaitu seperti sawi hijau, sawi daging, brokoli, selada air, paprika dan tomat. Hal ini sesuai dengan pernyataan (Wibowo \& Asriyanti, 2013) yang menyatakan bahwa jenis sayur yang mudah dibudidayakan adalah tanaman sawi. Selain itu menurut (Roidah, 2014) menyatakan bahwa tanaman berdaun seperti sawi, selada, brokoli mudah dibudidayakan dengan cara hidroponik. Sedangkan benih ikan yang digunakan yaitu lele dan nila. Hal ini sesuai dengan pernyataan (Effendi, 2000) komoditas budidaya perikanan dari kelompok ikan adalah ikan mas (Cyprinus carpio), gurame (Osphronemus gouramy), nila (Oreochromis niloticus), mujair (Oreochromis mossambicus), patin (Pangasius sp.), lele (Clarias sp.), tambakan (Helostoma temmincki), bawal, nilem (Osteochillus hasselti), tawes (Puntius javanicus), kowan (Ctenopharyngodon idella), koki (Carassius auratus), bandeng (Chanos chanos), belanak (Mugil chepalus), kerapu lumpur (Epinephelus tauvina), kerapu macan (Epinephelus fuscoguttatus), kerapu bebek (Cromileptes altivelis), kerapu sunu (Plectropomus leopardus), kakap putih (Lates calcarifer), baronang (Siganus sp.), kobia, dan napoleon

\section{b. Memberikan demplot aquaverticulture}

Memberikan demplot aquaverticulture sebagai saranana pembelajaran kepada ibu rumah tangga maka dilakukan pelatihan secara berkala melalui forum pertemuan ibu PKK dan ditentukan tempat yang akan dijadikan sebagai demplot.

c. Melakukan pelatihan teknik budidaya tanaman dan ikan dengan cara yang benar

Pelatihan ini dilakukan dengan cara memberikan informasi dan pelatihan dimulai pembibitan tanaman, jenis tanaman yang dapat digunakan, jenis nutrisi, jenis ikan yang dapat dibudidayakan melalui teknologi aquaveticulture, jenis pakan, serta bagaiman pemeliharaan tanaman dan ikan.

d. Melakukan pelatihan pengecekan kualitas air, kesehatan tanaman dan ikan.

Pelatihan ini merupakan pelatihan pemeliharaan tanaman dan ikan sedang yang dibudidaya, pelatihan ini dilakukan dengan cara pengecekan kualitas air secara konvensional berdasarkan kekeruhan dan aroma air. Menurut (Setyono, 2004) dalam proses budidaya ikan mencakup adanya biota air dan air sebagai media kultur oleh karena itu, pemahaman tentang kwalitas air sebagai me- dia kultur adalah sangat penting. Selain itu Kesehatan tanaman dan ikan tergantung pada kualitas air, jumlah pakan ikan dan nutrisi tanaman yang diberikan. Sehingga dalam perawatan maka yang perlu diperhatikan adalah komposisi pakan dan nutrisi serta jumlah ikan yang dibudidayakan.

\section{Pendampingan pendampingan dalam manajemen produksi hasil aqua vertikultur}

Metode pendampingan ini dilakukan setelah pasca panen, pelatihan ini bertujuan untuk membekali ibu rumah tangga dalam sistem pengelolaan hasil untuk kebutuhan sehari-hari 
Erfan Dani S,Livia Windiana, dan Nur Ocvanny A. 2018. Analisis Prilaku Ibu Rumah Tangga di Perkotaan Terhadap Pemanfaatan Teknologi Aquavertikulture Inovasi Pengembangan

Budidaya Pertanian dan Perikanan pada Lahan Sempit (Studi Kasus ibu PKK di Kelurahan Pandanwangi, Kecamatan Blimbing, Kota Malang )

Journal Viabel Pertanian. (2018), 12(2) 1-10

atau sebagai nilai tambah keuangan keluarga. Adapun pelatihan yang diberikan meliputi pendampingan dalam manajemen produksi yaitu pengolaan hasil panen, dalam pemasaran dan pendampingan dalam penetapan SOP,

\section{a. Pengolahan hasil panen sayuran}

Pendampingan ini bertujuan memberikan keterampilan dalam pengelolaan sayuran seperti pongolaan sayur sebagai keripik sayur, sehingga hasil panen sayur yang dihasilkan tidak hanya di makan segar atau dijadikan lalapan namun dapat ditingkatkan nilai ekonominya menjadi keripik sayur.
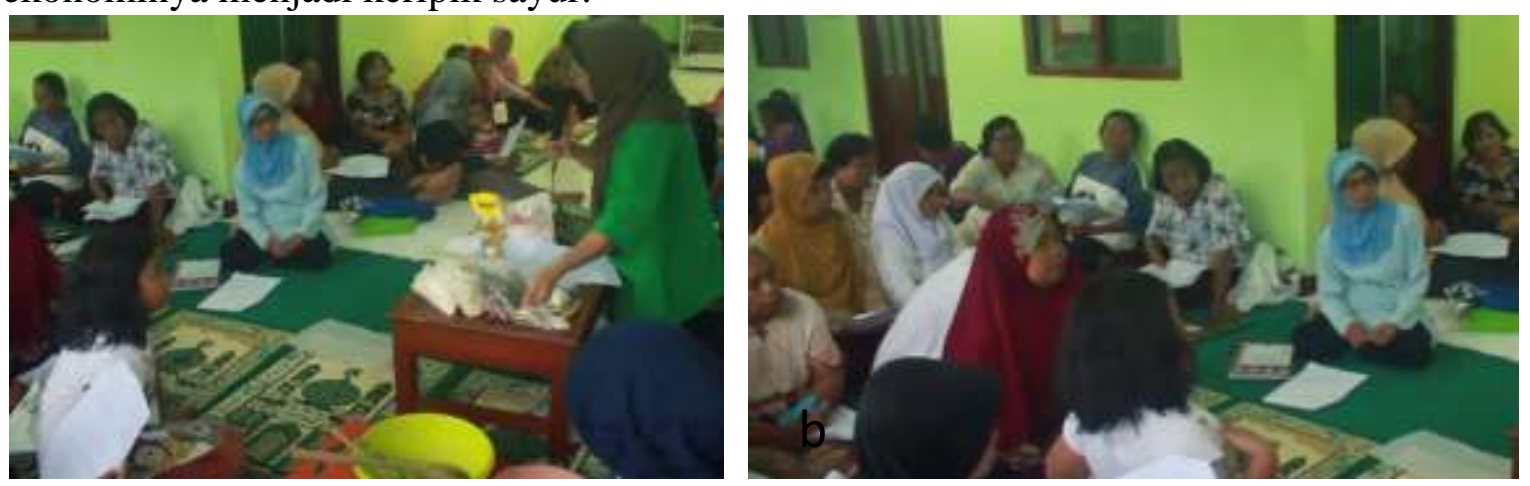

Gambar 2. Pengolahan hasil sayuran. Ket a. praktik pembuatan kripik sayur, b proses sosialisasi

\section{b) Pengolahan hasil panen ikan}

Pendampingan hasil panen ikan sama halnya dengan pendapingan hasil panen sayur yaitu bertujuan memberikan ketrampilan dan upaya peningkatan nilai ekonomi ikan segar adapun keterampilan yang diberikan kepada ibu rumah tangga yaitu pembuatan nuget ikan.
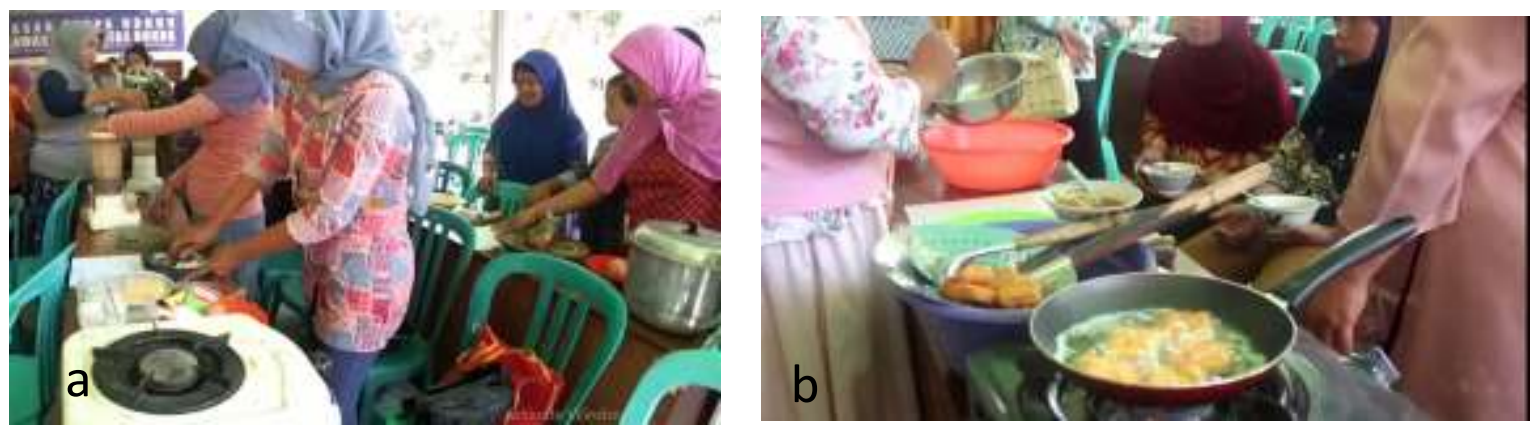

Gambar 3. Pengolahan hasil ikan. Ket a. praktik pembuatan nuget ikan, b hasil olahan nuget

\section{c) Pemasaran dan Penetapan SOP}

Pendampingan ini diberikan seperti pendampingan pembukuan dan pengenalan prospek pasar. Kemudian dari hasil keseluruhan pendampingan maka dibikin standart operasional prosedur.

\section{Evalusi Program Akuavertikultur}


Erfan Dani S,Livia Windiana, dan Nur Ocvanny A. 2018. Analisis Prilaku Ibu Rumah Tangga di Perkotaan Terhadap Pemanfaatan Teknologi Aquavertikulture Inovasi Pengembangan

Budidaya Pertanian dan Perikanan pada Lahan Sempit (Studi Kasus ibu PKK di Kelurahan Pandanwangi, Kecamatan Blimbing, Kota Malang )

Journal Viabel Pertanian. (2018), 12(2) 1-10

Adapun hasil evaluasi pada sebelum program akuavertikulture tertuang pada tabel 3 yaitu sebagai berikut:

Tabel 3. Hasil evaluasi quesioner dengan skala likert pada sebelum tahap sosialisasi aquaverticulture

\begin{tabular}{|l|l|c|c|}
\hline No. & \multicolumn{1}{|c|}{ Uraian } & $\begin{array}{c}\text { Nilai } \\
\text { Indeks (\%) }\end{array}$ & $\begin{array}{c}\text { Keterangan Nilai } \\
\text { Indeks }\end{array}$ \\
\hline 1. & $\begin{array}{l}\text { Penghasilan rumah tangga hanya berasal dari } \\
\text { pendapatan suami }\end{array}$ & 38 & Tidak Setuju \\
\hline 2. & $\begin{array}{l}\text { Anda ingin menunjang perekonomian rumah } \\
\text { tangga }\end{array}$ & 78 & Setuju \\
\hline 3. & $\begin{array}{l}\text { Anda ingin menghemat uang belanja sayur } \\
\text { mayur }\end{array}$ & 71.33 & Setuju \\
\hline 4. & Anda ingin menghemat uang belanja lauk pauk & 71.33 & Setuju \\
\hline 5. & $\begin{array}{l}\text { Anda ingin memberikan makan sehat bebas } \\
\text { residu kimia disetiap menu masakan sehari-hari }\end{array}$ & 70 & Setuju \\
\hline 6. & Anda senang bercocok tanam & 64 & Setuju \\
\hline 7. & Anda senang memelihara ikan & 56 & Netral \\
\hline 8. & Anda mengetahui tentang aquavertikulture & 38.67 & Tidak Setuju \\
\hline 9. & $\begin{array}{l}\text { Anda mengetahui aquavertikulture dari media } \\
\text { massa (cetak/online) }\end{array}$ & 38 & Tidak Setuju \\
\hline 10. & Anda tertarik menerapkan aquavertikulture & 76.67 & Setuju \\
\hline
\end{tabular}

Dari tabel 3 diatas menunjukan responden tidak setuju jika penghasilan rumah tangga hanya berasal dari pendapatan suami. Hal ini ditunjukan dengan nilai indeks 38\%. Tetapi responden setuju dan ingin menunjang perekonomian keluarga dengan menghemat uang belanja sayur mayur dan lauk pauk, selain itu responden juga ingin memberikan makanan sehat bebas residu kimia setiap harinya. Hal ini ditunjukan dengan nilai indeks masingmasing $78 \%, 71,33 \%, 71,33 \%$ dan $70 \%$.

Responden yang merupakan ibu rumah tangga juga senang bercocok tanam namun mereka netral terhadap pemeliharaan ikan. Hal ini ditunjukan dengan nilai indeks $64 \%$ dan $56 \%$. Dari hasil survey sebelum adanya penyuluhan mengenai aquavertikulture juga menemukan hasil bahwa responden belum mengetahui (tidak setuju) mengenai aquavertikultur baik dari media cetak maupun online. Namun setelah mendengar nama tersbut responden tertarik (setuju) untuk menerapkan aquavertikulture.

Selain itu kuesioner juga diberikan setelah adanya program sehinga didapatkan data seperti tabel 4. Hal ini digunakan sebagai pembanding antara sebelum dan sesudah program berlangsung yaitu sebagai berikut 
Erfan Dani S,Livia Windiana, dan Nur Ocvanny A. 2018. Analisis Prilaku Ibu Rumah Tangga di Perkotaan Terhadap Pemanfaatan Teknologi Aquavertikulture Inovasi Pengembangan

Budidaya Pertanian dan Perikanan pada Lahan Sempit (Studi Kasus ibu PKK di Kelurahan Pandanwangi, Kecamatan Blimbing, Kota Malang )

Journal Viabel Pertanian. (2018), 12(2) 1-10

Tabel 4. Respon ibu rumah tangga setelah adanya program aquaverticulture

\begin{tabular}{|c|c|c|c|}
\hline No. & Uraian & $\begin{array}{c}\text { Nilai } \\
\text { Indeks }(\%)\end{array}$ & $\begin{array}{l}\text { Keterangan } \\
\text { Nilai Indeks }\end{array}$ \\
\hline 1. & $\begin{array}{llll}\begin{array}{l}\text { Penyampaian } \\
\text { dipahami }\end{array} & \text { Program } & \text { Aquaverticulture } & \text { mudah } \\
\end{array}$ & 86 & Sangat Setuju \\
\hline 2. & $\begin{array}{lrrr}\text { Anda tertarik } & \text { untuk } & \text { menerapkan } & \text { Program } \\
\text { Aquaverticulture } & & & \end{array}$ & 82,67 & Sangat Setuju \\
\hline 3. & $\begin{array}{l}\text { Aquaverticulture merupakan inovasi yang dapat } \\
\text { meningkatkan usaha produktif ibu rumah tangga }\end{array}$ & 80 & Sangat Setuju \\
\hline 4. & $\begin{array}{l}\text { Alat dan bahan pembuatan aquaverticulture mudah } \\
\text { diperoleh }\end{array}$ & 74 & Setuju \\
\hline 5. & $\begin{array}{l}\text { Harga alat dan bahan aquaverticulture terjangkau } \\
\text { untuk anda }\end{array}$ & 71,33 & Setuju \\
\hline 6. & Pemasangan aquaverticulture mudah untuk diterapkan & 76 & Setuju \\
\hline 7. & $\begin{array}{l}\text { Rumah anda memiliki ruang yang memadai untuk } \\
\text { penempatan media aquaverticulture }\end{array}$ & 78 & Setuju \\
\hline 8. & $\begin{array}{l}\text { Penempatan media aquaverticulture dapat } \\
\text { mengganggu kondisi rumah anda }\end{array}$ & 53,33 & Netral \\
\hline 9. & $\begin{array}{lcccc}\text { Budidaya ikan } & \text { dan } & \text { sayuran } & \text { dengan } & \text { cara } \\
\text { aquaverticulture dirasa mudah untuk dilakukan } & \end{array}$ & 72,67 & Setuju \\
\hline 10. & $\begin{array}{l}\text { Program Aquaverticulture dirasa dapat menunjang } \\
\text { perekonomian keluarga }\end{array}$ & 78 & Setuju \\
\hline 11. & Aquaverticulture dapat memberikan dampak positif & 80,67 & Sangat Setuju \\
\hline 12. & Aquaverticulture dapat memberikan dampak negatif & 36,67 & Tidak Setuju \\
\hline
\end{tabular}

Berdasarkan tabel 4 di atas menunjukkan bahwa setelah dilakukannya Program Aquaverticulture responden merasa sangat setuju program ini mudah dipahami, adanya ketertarikan untuk menerapkan aquaverticulture, karena responden merasa sangat setuju bahwa aquaverticulture merupakan inovasi yang dapat meningkatkan usaha produktif ibu rumah tangga dan dapat memberikan dampak positif. Hal ini juga dapat dilihat selama program pengabdian dilaksanakan, terdapat antusiasme responden pada saat awal perkenalan program hingga penerapan program.

Selanjutnya, responden merasa setuju bahwa alat dan bahan pembuatan aquaverticulture mudah diperoleh, harganya terjangkau, mudah diterapkan, dan responden memiliki ruang yang memadai untuk penempatan media aquaverticulture. Selain itu responden juga setuju bahwa budidaya ikan dan sayuran secara aquaverticulture mudah untuk diterapkan dan dirasa dapat menunjang perekonomian keluarga. 
Erfan Dani S,Livia Windiana, dan Nur Ocvanny A. 2018. Analisis Prilaku Ibu Rumah Tangga di Perkotaan Terhadap Pemanfaatan Teknologi Aquavertikulture Inovasi Pengembangan Budidaya Pertanian dan Perikanan pada Lahan Sempit (Studi Kasus ibu PKK di Kelurahan Pandanwangi, Kecamatan Blimbing, Kota Malang ) Journal Viabel Pertanian. (2018), 12(2) 1-10

Namun, dalam program pengabdian ini responden merasa netral bahwa penempatan media aquaverticulture dapat mengganggu kondisi rumah, karena dari beberapa penjelasan responden menyebutkan bahwa lahan atau ruang kosong di rumah mereka tidak terlalu luas. Selanjutnya, responden merasa tidak setuju jika aquaverticulture dapat memberikan dampak negatif, karena selama program pengabdian ini berjalan memberikan hasil positif yaitu berupa sayuran dan ikan yang dapat dimanfaatkan responden untuk memenuhi kebutuhan pangan mereka.

\section{KESIMPULAN}

Adapun kesimpulan yang dapat diambil yaitu sebagai berikut.

1. Peningkatan usaha produktif para ibu rumah tangga tercermin pada tingkat antusias dan ketertarikan terhadap program aquaverticulture dan sebagian mampu menerapkan konsep tersebut pada areal rumahnya.

2. Program aquaverticulture merupakan program yang dapat meningkatkan usaha produktif ibu rumah tangga dalam membantu menyediakan kebutuhan ibu rumah tangga setiap harinya

\section{DAFTAR PUSTAKA}

Effendi, irzal ;mulyadi. (2000). Budidaya Perikanan, (21), 7815414.

Harahap, F. R. (2013). Dampak Urbanisasi Bagi Perkembangan Kota Di Indonesia. Jurnal Society, 1(1), 35-45.

Hendri, J. (2009). SKALA PENGUKURAN DAN TEKNIK PENSKALAAN. RISET PEMASARAN - UNIVERSITAS GUNADARMA -, 4-6.

Lukman, L. (2011). Teknologi Budidaya Tanaman Sayuran Secara Vertikultur. Teknologi Budidaya Tanaman Sayuran Secara Vertikultur, (517), 6. Retrieved from http://www.litbang.pertanian.go.id/berita/one/918/file/verikultur.pdf

Luthfia, agusniar rizka. (2013). menilik urgensi desa di era otonomi daerah. surakarta: jurnal of rural and development. Retrieved from https://jurnal.uns.ac.id/rural-anddevelopment/article/view/1858/1760

Roidah, I. S. (2014). Pemanfaatan Lahan Dengan Menggunakan Sistem Hidroponik. Jurnal Universitas Tulungagung BONOROWO Tahun, 1(2), 43-50. Retrieved from file://C:/Users/ASUS/Downloads/14-22-1-SM.pdf

Setyono, D. E. D. (2004). Pengetahuan Dasar Akuakultur. Oseana, XXIX(1), 27-32. Retrieved from www.oseanografi.lipi.go.id

Statistics Indonesia. (2014). Indonesia - Survei Sosial Ekonomi Nasional 2013. SocioEconomic/Monitoring Survey, 2014, 1-112.

Wibowo, S., \& Asriyanti, A. (2013). Aplikasi Hidroponik NFT pada Budidaya Pakcoy ( Brassica rapa chinensis ). Jurnal Penelitian Pertanian Terapan, 13(3), 159-167. 